\title{
QUÉ HACER CUANDO TODOS LOS PERIODISTAS SE HAN IDO
}

\author{
Por: David Lara Ramos
}

Todas las cámaras se han ido ya a otra guerra... Fin y principios, poema de Wislawa Szymborska

Este ensayo orienta su interés hacia la relevancia del relato periodístico del conflicto desde adentro de la historia, centrada en quienes la han vivido y contada por el periodista a partir del diálogo interior que le genera su interlocución con los protagonistas.

En las siguientes líneas se confrontan relatos ingenuamente sabios de las víctimas del conflicto armado en el Caribe colombiano con conceptos y apuestas de reconocidos cronistas de diferentes momentos históricos y procedencias; para advertir que unos y otros, desde orillas muy distintas, coinciden en la necesidad de contar la historia que la gente quiere contar, no la que el medio desea publicar.

El periodista está llamado a sacar en sus crónicas y reportajes lo que lleva dentro desde su diálogo con ese otro indispensable, como una forma de luchar contra la soledad.

Se trata de una especie de reivindicación de las voces enmudecidas; que deberían ser las más obvias, las más visibles, las que reclaman no seguir siendo tratadas como meros eventos, como simples anécdotas; porque son esas voces las que le dan verdadero sentido a la historia del periodista.

La escritora Alma Guillermoprieto asegura que su trabajo comienza cuando todos los periodistas se han ido. "Para mí es lo mejor, porque uno puede mirar cada detalle, preguntarse por las razones, y eso no puede hacerse cuando todos los periodistas están en un mismo lugar" (Diálogo en Cartagena, 2008). La propuesta de esta cronista mexicana resulta paradójica en una variedad de sentidos. El primero, está relacionado con la inmediatez como sinónimo de eficacia en la difusión de noticias, que ha hecho, en el mejor de los casos, que los periódicos opten por simplificar sus contenidos.

Se requiere así de un dato inmediato que satisfaga, en apariencia, la necesidad de estar informando. Otro, podría estar ligado a los medios como empresas 
que encontraron en la notica un contenido de venta rápida, en el que los periodistas se apegaron a normas y esquemas que estandarizaron su redacción.

El reportero de guerra polaco Ryszard Kapuscinski establece que el trabajo de los periodistas comenzó a cambiar en los años sesenta ante la presencia marcada de lo que llamamos corporativismo mediático y empresarial. El término utilizado por Kapuscinski para explicar esta transformación fue el anglicismo mediaworker, (trabajador de medios) que muestra cómo se dejó de lado la importancia del reportero y comenzaron a aparecer notas sin firma, hecho que es hoy cada vez más evidente, y que se refleja en frases impersonales como "La Agencia conoció...", "AFP estableció...", "Este medio encontró...", entre otros.

Para finales de los 60, el periodismo colombiano se estructuraba en ese corporativismo empresarial, y aquella prensa partidista que iniciaba todo tipo de controversias caracterizadas por catilinarias de ida y vuelta, y que acogió también a grandes literatos, en las décadas tempranas del siglo XX, cedió a la organización de empresas mediáticas, que tenían como objetivo empresarial la promoción de productos a través de sus páginas, acompañados de textos periodísticos en una variedad de formas.

Sobre la organización de los medios como empresas, la cual se dio en Colombia en los años sesenta y setenta, Gabriel Fonnegra (1984) escribe:

El tío, el padre, el abuelo, el tío abuelo, sentaron los cimientos sobre los cuales se levantan hoy los grandes y pequeños imperios de la prensa. Con el prestigio de su nombre y con el peso enorme del poder, la ambiciosa vanguardia logró depositar en mano de la generación siguiente diarios empresariales ya afianzados. Pero a los herederos, en justicia, hay que abonarle la modernización, notoria en los sesentas, y el empleo agresivo del boom publicitario: en grado tal que en medio de las quiebras y concordatos los 12 o 15 grandes rotativos parecen disfrutar de una salud de atleta (p.89).

Así, el periodismo partidista, al que el historiador Jacques Barzun (2001) prefiere llamar periodismo político, quedó confinado, relegado por nuevos estrategas de mercado, y gerentes visionarios que amalgamaron las perspectivas empresariales con la defensa exclusiva de ideales partidistas hoy cada vez más desdibujados. 
En ese escenario de periodismo partidista se gesta la oposición entre quienes están en el poder, y aquellos que lo anhelan. Esa tensa relación, Barzun (2001) la describe de la siguiente manera:

La prensa que ataca al gobierno sostiene que actúa en pro de la libertad y la justicia, contra la corrupción y por el bien general. La prensa que apoya al gobierno sostiene que informa al ciudadano ocupado o ignorante sobre las complejas actividades de los hombres del poder (p.468).

En ese uso agresivo del boom publicitario, como lo denomina Fonnegra (1984), y el ejercicio de un periodismo partidista, se construyó la fórmula que los medios siguen en la actualidad, y que ha generado emporios informativos cuya multiplicidad corporativa tiene hoy a la información, como punta de lanza de los negocios mediáticos o su herramienta más apreciada.

Hacia dónde se canalizaba toda esa riqueza narrativa, ese deseo de contar, ese anhelo por expresar de manera diferente nuestros sucesos, acorralados por una tendencia que organizaba las noticias en bloques de información con el propósito de llenar espacios con escritos de múltiples facturas. Un espacio que fue simplificado a centímetros cuando el diseño reclamó más libertad, y comenzó a avanzar la denominada dictadura de los diseñadores.

Sobre esa dictadura, Homero Alsina, editor y escritor uruguayo, le cuenta a la periodista Leila Guerriero una anécdota que refleja esa pugna por el espacio entre el periodista y el diseñador: "—El jefe de diagramación de Página/12 se llamaba Daniel Iglesias. También llamado "el Zorro" Iglesias, también llamado "no hay peor sordo que el Zorro Iglesias". Una vez entregué una nota que ni siquiera era mía. Me llaman de diagramación. "Sácale doce centímetros". Que sí, que no, la discusión subió de tono y viene el Zorro Iglesias y me dice: "¿Qué pasa con tu gente? ¿Son todos Shakespeare y Cervantes que no se les pueden cortar doce centímetros?". Le digo: "No, no son todos Shakespeare y Cervantes. Ahora, tu gente, ¿son todos Rembrandt y Velázquez que no se les puede cambiar el dibujito?" (En la crónica Vida del señor Sombrero).

Más adelante, comenta sobre un corto discurso que dio al recibir un homenaje en la escuela de periodismo Taller Escuela Agencia: "Jóvenes periodistas, ustedes han elegido una profesión que está llena de promesas, pero no se crean que es fácil. Porque cuando ustedes entren a un diario se van a encontrar con un jefe que les dice: 'Che, hay que hacer una nota a tal'. Vas y hacés la nota. La entregás. El jefe la mira y dice: 'Sí, está bien, pero faltaría tal y cual aspecto'. 
Vos vas y agregás tal y cual aspecto. Volvés. Y el jefe te va a decir: '¿Sabés lo que le falta a esto? Una entrada, un copete'. Vas, volvés con el copete. Te dice: 'Le falta un final, una cosa que restalle'. Lo encontrás. Terminás la nota y estás muy contento. ¿Y te creés que ahí terminó la cosa? No señor. Ahí la nota pasa al diagramador. Y el diagramador es un personaje que se dedica a quitarle doce centímetros a todas las notas... [...]".

La lucha por el espacio fue una disputa hoy soslayada con la idea del acceso a los medios y la facilidad de producción de contenidos en medios modernos y electrónicos, pero ese podría ser tema de otro texto.

Ese deseo de contar encontró en los suplementos literarios, creados en los años 80, para el caso del Caribe colombiano, lugares que reflejaron las apuestas creativas y narrativas de la época y fueron los espacios donde los escritores dejaron plasmadas sus historias y su deseo de contar.

El Nobel de literatura de 2000, Gao Xingjian, establece que "Escribir no es publicar, sino expresar lo que llevas dentro y luchar contra la soledad" (Entrevista de Amelia Castilla, El País de Madrid). A partir de esa singular reflexión, mencionamos ese "expresar lo que llevas dentro", porque allí comienzan a construirse las historias, los relatos que nos muestran y esa relación nos pone en contacto con el otro en una cercanía, que siento, es la forma más creativa de luchar contra la soledad o el olvido.

Contar es estar cerca al otro, es el vínculo entre aquel que se expresa en la medida que reconoce su realidad y siente el incontenible deseo de construir su relato, su crónica, su Historia, con mayúscula.

Si pensamos en una sociedad que no se cuenta, que no se hace protagonista de sus historias y sus personajes no brillan en sus relatos, su desaparición será una ruta posible, su referencia futura no alcanzará ni el destello de un mito y la duda sobre la existencia de ciertos hechos será asumida como un débil rumor del pasado.

Si se da el caso que otros sean los que nos cuenten o nos describan en sus escritos se corre el riesgo de ser dibujados, o lo que es peor simplificados, hecho tan peligroso como la desaparición, porque se crea mediáticamente un otro que en realidad no existe.

Resulta ambicioso proponerse establecer el origen, en nuestro medio, de ese "expresar lo que llevas dentro", para insistir en la frase de Xingjian, las 
referencias de esos textos que nos cuentan, los podríamos ubicar a finales del siglo XIX y comienzos del siglo XX, para no irnos, como es recurrente, a los llamados Cronistas de India, cuyas formas se regían por antiguos tratados de retórica y sus visiones y asombros crearon una especie de lugar mágico lleno de figuras, criaturas y monstruos que terminaron construyendo relatos fantásticos, por no decir falsos, de la reciente realidad que tenían antes sus ojos.

Para el siglo XIX y comienzos del XX, el momento de mayor revitalización creativa, los escritores estaban más preocupados por estéticas y narrativas que les permitieran una relación próxima con el lector, utilizando abordajes originales en una variedad de estilos.

Esa crónica de principios de siglo XX, ha encontrado dificultades para su clasificación en contraposición a la visión canónica y más extendida de crónica, como organización de hechos sucesivos.

Maryluz Vallejo (1997) en su libro La crónica en Colombia medio siglo de oro escribe: "La crónica, territorio sin fronteras, se convierte así en uno de los géneros de experimentación más fascinantes que existen en el periodismo literario para explorar lo personal y lo universal... (Introducción XII, 1997). Esa apreciación está más cerca de ese "expresar lo que llevas dentro", que propone Xingjian y en últimas, la razón de sentarse a escribir.

Vallejo concluye que hablar de esa crónica personal a la cual ella considera como "clásica" tiene además elementos del artículo y la columna, y las tres personas (el cronista, el articulista y el columnista) "[ ... . responden al misterio de la Santísima Trinidad: son una sola persona (Introducción XV).

Para no dejar todo en los caminos místicos del misterio, Vallejo hace una clasificación que nos acerca a preferencias temáticas o abordajes estilísticos, subrayando al final que una de las principales características del género es precisamente (o imprecisamente) su plasticidad.

En ese afán clasificatorio el aporte de narradores norteamericanos ha sido relevante. Fueron ellos quienes para finales de los años 60 denominaron a estos relatos personales crónicas informativas, que elaboraban con las técnicas del llamado periodismo literario que se nutrió de grandes novelistas del siglo XIX como Nathaniel Hawthorne, Hernán Melville o Ambrose Bierce, entre otros, y que fue el antecedente de lo que el periodista Tom Wolfe, anunciara como "nuevo periodismo". 
Ese nuevo periodismo lanzó el primer ataque a la noción de objetividad, considerada patrimonio del periodismo, sinónimo de la verdad, y puso en el centro del relato al sujeto que observa, describe, analiza, e interpreta la realidad. Un nuevo periodismo que se vale de las técnicas de la reportería, de investigar sobre qué ha pasado, sin la inmediatez que rige a los medios actuales, pero sí con el afán de contar aquella realidad que no pasa por las noticias. Eso en palabras de Alma Guillermoprieto, solo es posible cuando todos los periodistas se han ido.

Guillermoprieto educada con los estándares del nuevo periodismo, llegó muy joven a cubrir la guerra de El Salvador en los años 80. Alma encontró en formas menos esquemáticas la manera de expresar lo que llevaba dentro, a la manera de Xingjian, con la idea de contar más allá de la cifra de muertos, del hecho descontextualizado, o el mero enunciado de nombres y lugares, sin mencionar las recurridas declaraciones de funcionarios que intentan imponer la voz oficial y los periodistas son usados como grandes megáfonos que propagan y repiten esas versiones.

En el prólogo de La descripción del mundo, de Marco Polo, el célebre viajero, luego de anunciar las maravillas que contara de sus viajes advierte: "Y así os lo contará el libro con orden, tal como micer Marco Polo ciudadano sabio y noble de Venecia, en él las cuenta y por sí mismo las vio. Empero hay cosas que él mismo no vio, que a sus oúdos llegaron en boca de personas dignas de toda fe, y así las cosas vistas las dirá como vistas y las demás como oídas, para que de esta suerte nuestro libro sea verdadero y sin mentira alguna". Y comenzó a relatar.

En el mismo prólogo establece la necesidad de contar, de hacer memoria, de expresar aquello que llevas dentro y que Marco Polo vivió entre 1282 y 1295 : "Y pensó luego que habría sido gran desventura no dejar escritas todas aquellas maravillas que sus ojos vieron, de suerte que quienes no las supieran pudiesen conocerlas por este libro".

Como cronista uno podría hacer un inventario de aquellos momentos vividos y que propician otras lecturas más allá de la noticia que se construye para el día siguiente. Me permitiré hablar de mi trabajo de memoria de realidades del Caribe, con la sensata reflexión ligada a que muchos de los relatos que se cuentan están allí porque el cronista los ha vivido y no hay otra forma de contarlos sino a través de aquel que de manera privilegiada se introduce en la realidad que contará. El escritor y periodista Gustavo Arango lo dice de manera más simple: "El trabajo del cronista es el cronista en la crónica" (Recuerda el alma dormida, 2013). 
En 2008, regresé a Chengue, Sucre, donde en 2001, un grupo de 80 paramilitares dio muerte a 27 personas. Entrevisté a muchas mujeres, entre ellas a Tulia Meriño. Su grupo de amigas y familiares preparaban pasteles, días antes de la Navidad. Una frase pronunciada por Luz Marina, una de las mujeres que había permanecido siempre en silencio durante la conversación, dio una visión diferente sobre el impacto de una masacre en la vida de un pueblo.

Ellas alababan las bondades del lugar y dije que quisiera hacerles un comentario porque siempre se referían a su pueblo como "Chengue fue..." "Chengue era..." "Chengue tenía..." "En Chengue había..." como si el pueblo hubiera desaparecido". Recuerdo que Chepa y Nacha guardaron silencio, se miraron en busca de una posible respuesta; y fue cuando aquella firme y pausada voz de Luz Marina o "Luzma", como le decían, soltó la única frase que pronunció en toda la noche, luego de preguntarles "si acaso no pensaban volver y recuperar esa maravilla de pueblo del que habían estado hablando". "Oiga", interpeló Luzma, al tiempo que cortaba con un cuchillo una hoja de bijao, puso el cuchillo sobre la mesa y me dijo: "Vea... para que entienda, que usted parece que no entiende... uno no puede regresar a un lugar que ya no existe".

Hoy cada vez que hablan de retornar a la tierra a pesar de muchas experiencias exitosas creo que es cierto, el pueblo que era, el que estaba, ya no existe y sus referentes de hoy están marcados por aquello que pasó, pero encuentro en el relato nuevos sentidos para reflexionar sobre las visones de aquellos que sufrieron la tragedia de una masacre.

En otro aparte de esa misma crónica, Jaime, campesino de unos 70 años, comenta sobre la pérdida de una cosecha de aguacates, y la historia es tan fantástica que uno difícilmente la encuentra en los textos de ficción, es como si la realidad se empeñara en convencer a los escritores de ficción que se hace imposible que su imaginación la supere.

En la terraza de la casa me explicaba que la gente podía retornar al pueblo si mejoraban las condiciones, y me dice: "Le voy a poner un ejemplo de lo que pasa, yo regresé el 11 de septiembre de 2006. En 2007, más o menos entre marzo y mayo, se dio la cosecha de aguacate, que es el producto que más ganancias deja, y resulta... présteme atención a lo que le voy a decir... en tres hectáreas sembradas de aguacate uno corta semanalmente entre seis mil y ocho mil unidades, pero el año pasado, por las condiciones de la vía, no pudimos sacar el producto... yo perdí más de 30 mil aguacates, igualito pasó con otra gente". Osman, sobrino de Jaime, interrumpe para contar que en las fincas, el gallinazo comenzó a comerse todo el aguacate que se perdía: "Entonces — sigue Osman con su relato- me imagino 
yo que será por la grasa, las plumas, comenzaron a caérseles, y vea... quedaban todos esos animales, hartos de aguacate, como gallinas negras, desplumadas, con el pescuezo pelao, rondando por las fincas, y las plumas rodando por el suelo, como hojas cubriendo la tierra".

Cada vez que leo esta historia de los goleros en Chengue que se comieron la cosecha de aguacate de 2007 me pregunto por sus simbolismos y su representación, pero cada vez que lo intento la única idea que me sobrecoge es pensar que esa historia estaba allí y alguien la contó. Es la opción que nos debemos no solo cuando los periodistas se van sino también cuando no llegan. En una de las salas de la Fundación para un Nuevo Periodismo Iberoamericano se le preguntó al periodista polaco Ridzard Kapushinski a qué atribuía su éxito como escritor y cronista. El maestro guardó silencio. Se encogió de hombros como si no comprendiera la pregunta y dijo: "La verdad es que creo que se debe a que en muchos de los lugares donde estuve, el único periodista que había allí era yo, nadie más había llegado".

Uno puede llegar a pensar que las plataformas tecnológicas de información satisfacen el deseo de saber del público, sin embargo tales avances son aún incapaces de narrarnos, porque para hacerlo se necesitan aquellos que piensen más en habitar una realidad sin afanes para luego contarlo

Ken Doctor, periodista, asesor de medios desde New York Times hasta Netflix, al preguntársele por las posibles caminos de la noticia, comenta: "La idea es mostrar la importancia de los buenos reportajes, pues de ellos depende que los ciudadanos puedan tomar decisiones (El Espectador, mayo 27, 2014)". Luego se le preguntó: ¿Qué deben aprender las nuevas generaciones de periodistas? Su respuesta fue tan simple como alentadora: "Es importante aprender a contar todo tipo de historias de maneras distintas", al tiempo que entrega la sugerencia a los nuevos reporteros: "Aprendan las herramientas básicas de la reportería".

Fue una grata sorpresa, leer que un experto en consumos mediáticos en la era digital, anima a los periodistas a que se entrenen en ir a ver qué pasa, a dialogar con la gente, a vivir experiencias vitales para hacer las crónicas que construyan la memoria, que otros no cuentan, en vez de andar entretenidos en novedosos dispositivos electrónicos para conseguir sus noticias. Cuando todas las cámaras se hayan ido a otra guerra, como escribe la poetisa Wislawa Szymborska, comenzará entonces el trabajo de narrar aquello que no se narró por prisa, por el poder de los grandes medios, o porque ha llegado el anuncio de una nueva tragedia. 